\title{
Role and therapeutic value of dendritic cells in central nervous system autoimmunity
}

\author{
FJ Quintana ${ }^{\star, 1}$, A Yeste $^{1}$ and ID Mascanfroni ${ }^{1}$
}

Dendritic cells (DCs) are professional antigen-presenting cells that control the generation of adaptive immunity. Consequently, DCs have a central role in the induction of protective immunity to pathogens and also in the pathogenic immune response responsible for the development and progression of autoimmune disorders. Thus the study of the molecular pathways that control DC development and function is likely to result in new strategies for the therapeutic manipulation of the immune response. In this review, we discuss the role and therapeutic value of DCs in autoimmune diseases, with a special focus on multiple sclerosis.

Cell Death and Differentiation (2015) 22, 215-224; doi:10.1038/cdd.2014.125; published online 29 August 2014

\section{Facts}

- Dendritic cells (DCs) control central and peripheral tolerance through their effects on effector and regulatory T cells.

- Specific signaling pathways regulate the ability of different DC populations to promote effector and regulatory T-cell responses.

- Abnormalities in DC numbers, recruitment and function contribute to the pathology of multiple sclerosis (MS) and can be partially overcome by the use of disease-modifying therapies and the targeting of specific molecular pathways.

- Nanotechnology provides new tools for the modulation of DC activity in vivo and the therapeutic induction of antigenspecific tolerance in immune-mediated disorders.

\section{Open Questions}

- Although DC populations that promote the development of forkhead box $\mathrm{P} 3$-positive $\left(\mathrm{FoxP}^{+}\right)$regulatory $\mathrm{T}$ cells (Tregs) have been identified, it is not yet clear whether these populations constitute separate tolerogenic DC lineages or represent alternative activation or maturation states of other DC populations.

- What are the different molecular pathways that control the DC's ability to prime effector or tolerogenic T-cell responses?
- There is an unmet clinical need for the development of methods for the efficient and consistent generation of tolerogenic DCs in vitro and in vivo that can be implemented in large-scale clinical setups.

Dendritic cells (DCs) are professional antigen-presenting cells (APCs) that control the activation and polarization of $T$ cells into specific lineages and, consequently, the generation of antigen-specific antibody and T-cell responses. ${ }^{1}$ In the context of an infectious challenge, the induction of pathogenspecific immune responses provides protective immunity to fight the infection. However, in the context of autoimmune diseases DCs regulate the balance between pathogenic and regulatory immune mechanisms, controlling disease onset and progression. Thus, DCs have a central role in the control of the adaptive immune response to pathogens and selftissues and therefore constitute potential targets for the therapeutic modulation of the immune response. In this review, we discus the role of DCs in autoimmune diseases, with a special emphasis on their role in the modulation of central nervous system (CNS) inflammation in MS.

\section{Classes of DCs}

Two major classes of DCs have been identified based on their morphological and functional characteristics (Figure 1): conventional or classical DCs (cDCs) and plasmacytoid DCs

\footnotetext{
${ }^{1}$ Department of Neurology, Center for Neurologic Diseases, Brigham and Women's Hospital, Harvard Medical School, Boston, MA, USA

${ }^{*}$ Corresponding author: FJ Quintana, Department of Neurology, Center for Neurologic Diseases, Brigham and Women's Hospital, Harvard Medical School, 77 Avenue Louis Pasteur, HIM 714, Boston, MA 02115, USA. Tel: + 1617525 5317; Fax: + 1617525 5305; E-mail: fquintana@ rics.bwh.harvard.edu

Abbreviations: AHR, aryl hydrocarbon receptor; AP-1, activator protein 1; APC, antigen-presenting cell; Batf3, basic leucine zipper transcription factor, ATF-like 3; CCL3, chemokine (C-C motif) ligand 3; CCR5, chemokine (C-C motif) receptor 5; CD, cluster of differentiation; CDC, conventional or classical dendritic cell; CNS, central nervous system; DC, dendritic cell; EAE, experimental autoimmune encephalomyelitis; FDA, US Food and Drug Administration; Flt3L, FMS-like tyrosine kinase 3 ligand; FoxP3, forkhead box P3; GA, glatiramer acetate; gp130, glycoprotein 130; IDO, indoleamine 2,3-dioxygenase; IFN, interferon; IFNAR, interferon alpha/beta receptor; IL-27R $\alpha$, interleukin 27 receptor alpha; IRF8, interferon regulatory factor 8; ITE, 2-(1'H-indole-3'-carbonyl)-thiazole-4-carboxylic acid methyl ester; KLF4, Kruppel-like factor 4; MAPK, mitogen-activated protein kinase; MHC class II, major histocompatibility complex class II; MS, multiple sclerosis; mTEC, medullary thymic epithelial cell; $\mathrm{NF}-\kappa \mathrm{B}$, nuclear factor $\kappa \mathrm{B}$; NLRP3, NLR (NOD-like receptor) family, pyrin domain containing 3; NP, nanoparticle; pDC, plasmacytoid dendritic cell; RelB, v-rel avian reticuloendotheliosis viral oncogene homolog B; RIPgp/B6 model, rat insulin promoter expressing glycoprotein of LCMV virus, in C57BL/6 mice; RRMS, relapsing remitting MS; Spi-B, Spi-B transcription factor (Spi-1/PU.1 related); SPMS, secondary progressive MS; STAT1, signal transducer and activator of transcription 1; Th, Thelper; TLR, Toll-like receptor; Tr1, FoxP3 ${ }^{-}$IL-10+ type 1 regulatory T cells; Treg, FoxP3 ${ }^{+}$regulatory T cell; Zbtb46, zinc finger and BTB domain containing 46 Received 12.6.14; accepted 23.6.14; Edited by H-U Simon; published online 29.8.14
} 


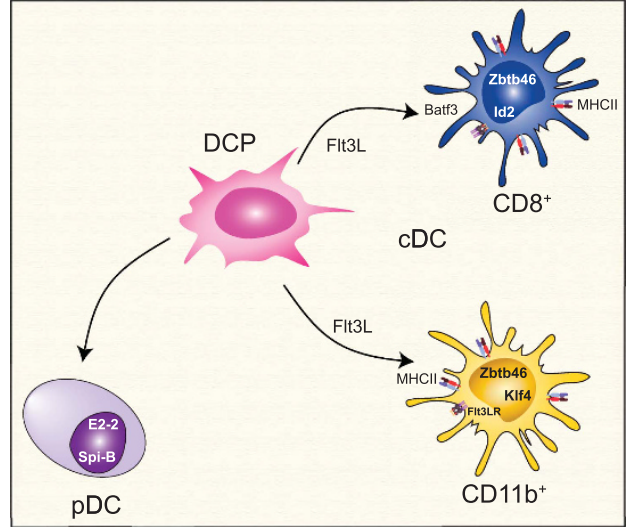

Figure 1 Classes of DCs. Two major classes of DCs have been identified based on their morphological and functional characteristics: conventional or classical DCs (cDCs) and plasmacytoid DCs (pDCs). They are differentiated from a common dendritic cell precursor (DCP) in a process controlled by lineage-specific transcriptional programs

(pDCs). ${ }^{2-4}$ The differentiation and function of cDCs and $\mathrm{pDCs}$ is associated with specific transcriptional programs that show some overlap, such as their dependency on interferon regulatory factor 8 (IRF8), ${ }^{5,6}$ but are mainly controlled by lineage-specific elements.

cDCs present a characteristic dendritic morphology and are highly phagocytic cells that express high levels of major histocompatibility complex class II (MHC class II) and are endowed with potent APC function. CDCs have a short half-life and are constantly replaced from bone marrow precursors generated in a FMS-like tyrosine kinase 3 ligand (Flt3L)dependent manner. ${ }^{7}$ At the molecular level, the generation of cDCs is controlled by transcription factor Zbtb46 (zinc finger and BTB domain containing 46$)^{8,9}$ and also by the transcription factors B-cell lymphoma 6 proteinv-rel avian reticuloendotheliosis viral oncogene homolog $B$ and IRF4. ${ }^{10-13}$

Two major subsets of cDCs have been identified: cluster of differentiation $8 \alpha^{+}\left(\mathrm{CD} 8 \alpha^{+}\right) \mathrm{cDCs}$ and CD11b ${ }^{+}$cDCs. ${ }^{1,2,4,14}$ $\mathrm{CD} 8 \alpha^{+}$cDCs efficiently present exogenous antigens to $\mathrm{CD}^{+}{ }^{+} \mathrm{T}$ cells; these cells also require Id2 and basic leucine zipper transcription factor, ATF-like 3 (Batf3) for their differentiation, ${ }^{15,16}$ but a Batf3-independent pathway has also been described for their generation. ${ }^{17} \mathrm{CD}_{11 \mathrm{~b}}{ }^{+} \mathrm{cDCs}$ preferentially activate $\mathrm{CD} 4^{+} \mathrm{T}$ cells and require Kruppel-like factor 4 for their differentiation. ${ }^{18}$

pDCs present a spherical shape that resembles plasma cells and produce high amounts of type I interferons following Toll-like receptor 7 (TLR7) or TLR9 activation. ${ }^{3,19}$ pDCs are not phagocytic and are considered inefficient inducers of $\mathrm{CD}^{+}{ }^{+}$T-cell responses. Similarly to $\mathrm{cDCs}, \mathrm{pDCs}$ are also derived from bone marrow progenitors in an Flt3L-dependent manner. ${ }^{20,21}$ The development of pDCs is promoted by the transcription factor basic helix-loop-helix transcription factor (E protein) $^{22,23}$ with the contribution of Spi-B transcription factor (Spi-1/PU.1 related). ${ }^{24}$

\section{Function of DCs in CNS Autoimmunity}

In the context of MS and its model experimental autoimmune encephalomyelitis (EAE), DCs have important roles related to the generation of the T-cell repertoire and the activation and polarization of myelin-specific T cells in the periphery and the CNS (Figure 2).

Role of DCs in central tolerance. Central tolerance is enforced by the thymic expression of tissue-specific antigens such as myelin proteins in medullary thymic epithelial cells (mTECs) driven by the transcription factor autoimmune regulator. ${ }^{25-27}$ The expression of peripheral antigens in mTECs results in the depletion of high affinity self-reactive clones and the differentiation of natural Tregs. ${ }^{27-29}$ Thymic DCs cross-present tissue-specific antigens expressed by mTECs. ${ }^{30,31}$ Moreover, peripheral DCs migrate to the thymus where they present peripheral antigens. ${ }^{32,33}$ Taken together, these observations suggest that DCs participate in the maturation of $\mathrm{T}$ cells and the generation of FoxP3 ${ }^{+}$Tregs in the thymus. However, the depletion of DCs does not affect thymic T-cell maturation and $\mathrm{FoxP}^{+}$Treg generation, suggesting that the contribution of DCs to these processes is minimal. ${ }^{34}$ Nevertheless, it is possible that DCs participate in the enforcement of tolerance to a specific subset of antigens or under specific conditions.

Role of DCs in the peripheral activation of $T$ cells. Dendritic cells also have a significant role in peripheral tolerance. The delivery of antigen to DCs using antibody or transgene-based strategies induces profound $\mathrm{CD}^{+}$and $\mathrm{CD}^{+}$T-cell tolerance. ${ }^{35-37}$ The induction of immune tolerance as a result of antigen delivery or expression in DCs is associated with the induction of $\mathrm{CD}^{+}{ }^{+} \mathrm{FoxP}^{+}$ Tregs. Indeed, DCs promote the differentiation of FoxP3 ${ }^{+}$ Tregs via the production of TGF $\beta 1$, retinoic acid and kynurenine. ${ }^{38-41}$ DCs can also promote the differentiation of FoxP3 ${ }^{-}$interleukin (IL)-10 ${ }^{+}$type 1 regulatory T cells (Tr1 cells) through several mechanisms, including the production of IL-27. ${ }^{42-44}$ DCs contribute not only to the differentiation but also to the maintenance of $\mathrm{FoxP}^{+}$Tregs in the periphery through CD80 and CD86-dependent interactions. ${ }^{45}$ Conversely, although the removal of cDCs and pDCs does not result in spontaneous autoimmunity, their removal results in the worsening of EAE and decreased levels of FoxP3 ${ }^{+}$ Tregs. ${ }^{46}$ Taken together, these data suggest that DCs can control peripheral tolerance through their effects on the generation and maintenance of Treg populations under homeostatic and inflammatory conditions.

Please note that although it has been postulated that specific DC populations promote the development of FoxP3 ${ }^{+}$ Tregs $^{38,40}$ and $T r 1^{43}$ cells in vivo, it is not yet clear whether these populations constitute specific tolerogenic DC lineages or represent alternative activation or maturation states of DCs. ${ }^{47-49}$

Following activation, DCs can promote the differentiation of effector T cells that drive CNS autoimmunity. Several APC populations can promote T-cell activation and polarization. However, the transgenic expression of MHC class II in DCs is sufficient to recover the susceptibility to EAE of otherwise disease-resistant MHC class II-deficient mice. ${ }^{50}$ It should also be noted that EAE can be induced in the absence of DCs, ${ }^{46}$ indicating that although DCs are sufficient to induce CNS autoimmunity, other APCs can also promote the 
Neuroinflammation

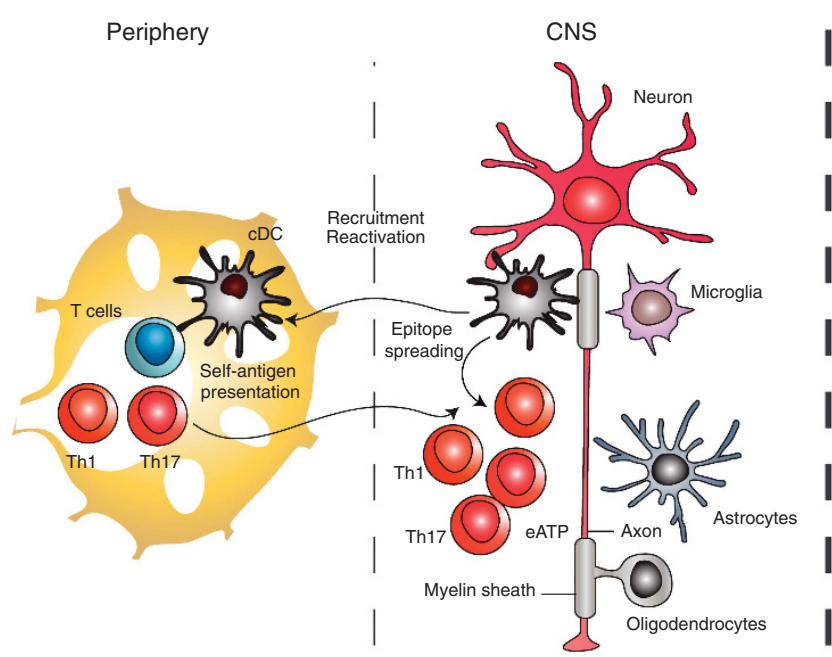

Neuroprotection

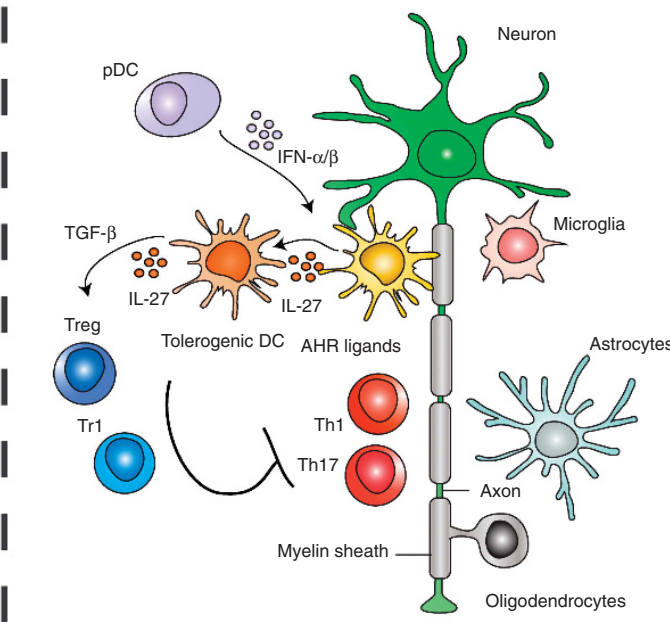

Figure 2 Function of DCs in CNS autoimmunity. In the context of CNS autoimmunity DCs have pro- and anti-inflammatory roles. DCs boost neuroinflammation by promoting the activation of effector T cells, their recruitment and reactivation in the CNS, resulting in the spreading of the pathogenic immune response. DCs also promote the differentiation of FoxP3 ${ }^{+}$Tregs via the production of TGF $\beta 1$, retinoic acid and kynurenine; DCs can also promote the differentiation of Tr1 cells through the production of IL-27

differentiation of pathogenic $\mathrm{T}$ cells. Taken together, these data suggest that different signaling pathways in DCs control their ability to promote the differentiation of regulatory and effector T-cell responses. For example, the mitogen-activated protein kinase $\mathrm{p} 38 \alpha$ is needed for the differentiation of T helper type 17 (Th17) cells by DCs. ${ }^{51}$ The identification of these pathways has the potential to lead to new therapeutic approaches for MS and other immune-mediated diseases.

Role of DCs in the activation of T cells in the CNS. The role of DCs in CNS autoimmunity is not restricted to the polarization of $T$ cells in peripheral immune organs. DCs secrete chemokines that promote $\mathrm{T}$-cell recruitment and reactivation in the CNS. ${ }^{52}$ Epitope spreading, the diversification of epitope specificity from the initial epitope-specific immune response to additional epitopes on the same or different antigens, is thought to have an important role in CNS autoimmunity. ${ }^{53}$ Miller and coworkers identified a subpopulation of $\mathrm{F} 4 / 80^{-} \mathrm{CD} 11 \mathrm{C}^{+} \mathrm{CD} 45^{\text {hi }}$ DCs that infiltrate the CNS and promote epitope spreading in mouse models of MS. ${ }^{54}$ They also reported that CNS-infiltrating CD11b ${ }^{+}$DCs preferentially polarize $\mathrm{T}$ cells into the Th17 lineage. ${ }^{28,29}$ However, not all CNS-infiltrating DCs promote inflammation. pDCs were found to limit the differentiation of effector Th1 and Th17 cells in the EAE model in an indoleamine 2,3dioxygenase (IDO)-dependent manner; these effects are not associated with the differentiation of FoxP3 ${ }^{+}$Tregs. $^{55}$ Taken together, these data show that, both in the periphery and the CNS, DCs control the balance between effector and regulatory $T$ cells and consequently the development of autoimmune disorders.

\section{Phenotype and Function in MS}

MS is a chronic demyelinating autoimmune disease of the CNS. $^{56}$ In most patients, MS initially presents a relapsing-remitting clinical course (relapsing-remitting MS (RRMS)) that is followed by a progressive phase (secondary progressive MS (SPMS)) characterized by the continued and irreversible accumulation of disability. ${ }^{57}$ High numbers of cDCs and pDCs accumulate in the cerebrospinal fluid and white matter of MS patients, ${ }^{58,59}$ and DC abnormalities have been associated with different stages of the disease.

Circulating cDCs in RRMS and SPMS present an activated phenotype and produce increased levels IL-12p70 and IL-23p19. ${ }^{60-62}$ Moreover, circulating cDCs in RRMS show increased expression of activation markers and chemokine (C-C motif) receptor 5 (CCR5) than healthy controls. ${ }^{63,64}$ Interestingly, the expression of the CCR5 ligands chemokine (C-C motif) ligand 3 (CCL3) and CCL5 is increased in MS CNS lesions, ${ }^{65}$ and CCR5 polymorphisms have been linked to changes in disease onset and activity, ${ }^{66,67}$ suggesting that this pathway contributes to the recruitment of $\mathrm{cDCs}$ to the inflamed CNS of MS patients.

Following TLR9 activation, circulating pDCs from RRMS patients show diminished production of interferon (IFN)- $\alpha .{ }^{68}$ Moreover, pDCs from MS patients show a decreased ability to influence Tregs. ${ }^{68}$ Thus, it is possible that deficits in pDCs contribute to disease pathology. Of note, however, several findings on PDC in MS have not always been replicated by independent groups, and it has been suggested that specific pDC subpopulations (e.g., pDC1 versus pDC2) are affected in MS. ${ }^{69}$

\section{Effect of MS Disease-Modifying Therapies on DCs}

The data shown in the previous section highlights the abnormalities in DC numbers, recruitment and function associated with MS. These abnormalities are likely to contribute to MS pathology and its response to therapy. Thus the study of the effects of therapy on DCs might provide information regarding mechanisms of disease pathogenesis in MS and potential therapeutic interventions. 
Type I interferon signaling through IFN alpha/beta receptor has profound effects on DCs, diminishing their ability to promote the differentiation of effector $\mathrm{T}$ cells ${ }^{70-72}$ and limiting CNS inflammation during EAE. ${ }^{73-75}$ IFN- $\beta$ administration, a first-line therapy for MS, affects both pDCs and cDCs. IFN- $\beta$ treatment decreases the numbers of circulating $\mathrm{CDC}$ in RRMS, without affecting pDCs. ${ }^{69}$ At the functional level, monocyte-derived DCs show decreased IL12p70 production and produced increased amounts of IL-10 following treatment with IFN- $\beta .^{76}$ In addition, IFN- $\beta$ treatment induces an antiinflammatory phenotype in pDCs, characterized by the upregulation of PDL1 and IL-10 expression. ${ }^{76}$ Finally, IFN- $\beta$ also induces the production of IL-27 by DCs, a cytokine with broad anti-inflammatory effects. ${ }^{77}$

Glatiramer acetate (GA) is an immunomodulatory drug currently used to treat MS. Treatment with $G A$ is associated with a decreased production of TNF- $\alpha$ and IL-12p70 by monocyte-derived DCs, reduced CD40 expression and reduced pro-inflammatory activity in pDCs. ${ }^{78-81} \mathrm{GA}$ has also been shown to induce type II anti-inflammatory monocytes that share some functional and phenotypic characteristics with anti-inflammatory DCs and have an important role in the therapeutic effects of GA in MS. ${ }^{82}$ Thus it is possible that similar molecular mechanisms operate in the induction of antiinflammatory DCs and type II monocytes by GA.

Laquinimod is a new oral immumodoulatory agent that is under development for the treatment of RRMS. ${ }^{83-86}$ Among other effects, Laquinimod has been shown to modulate the $T$-cell response in rodents and humans as a result of its effects on signal transducer and activator of transcription 1 (STAT1), mitogen-activated protein kinase and NF- $\kappa$ B signaling in DCs. ${ }^{87,88}$ Thus, by modulating DC function, Laquinimod might alter the balance between effector and regulatory $T$ cells and therefore suppress the pathogenic T-cell response that drives RRMS.

Taken together, these data suggest that the modulation of DC activity is a potential therapeutic approach for MS and other immune-mediated diseases, particularly for the re-establishment of antigen-specific tolerance. However, these drugs were not specifically designed to target DCs and obviously affect many cell types and biological processes in vivo, potentially leading to unwanted side effects. Thus the study of the pathways that control DC activity might lead to the development of new and more effective therapies for autoimmunity.

\section{Regulation of DC Activity}

Newly generated immature cDCs have strong phagocytic activity but express relatively low levels of $\mathrm{MHC}$ and costimulatory molecules, resulting in a limited capacity to activate $\mathrm{T}$ cells. The activation of $\mathrm{cDCs}$ by microbial or inflammatory signals triggers a cascade of signaling pathways that boost the expression of MHC and costimulatory molecules and, consequently, the ability of $\mathrm{cDCs}$ to induce adaptive immune responses. Interestingly, the analysis of the transcriptional response to stimulation suggest that most of the chromatin marks in DCs are established during the development of DCs and are not affected by their activation, while a limited number of transcription factors and signaling pathways mediate the maturation of DCs and potentially their ability to activate T cells. ${ }^{89,90}$ The pathways that regulate DC activation have been extensively discussed elsewhere; in the following sections, we will focus on a handful of pathways of interest.

Nuclear factor $\boldsymbol{\kappa} \mathrm{B}$ (NF- $\kappa \mathrm{B})$. The transcription NF- $\kappa \mathrm{B}$ signaling has a central role in DC activation and the transcriptional programs that regulate their ability to activate and polarize T cells. ${ }^{89,91-93}$ Because of its important role in the immune response, NF- $\kappa \mathrm{B}$ activity is tightly regulated. One important regulator of $\mathrm{NF}-\kappa \mathrm{B}$ is the $\mathrm{A} 20$ ubiquitin-editing enzyme. ${ }^{94}$ A20 catalyzes the removal of $\mathrm{K} 63$ linked poly ubiquitin chains (which activate signaling) and the addition of K48 poly ubiquitin chains, which promote proteasomal degradation. A20 controls the ubiquitination of several proteins involved in $\mathrm{NF}-\kappa \mathrm{B}$ signaling and regulation, actively limiting NF- $\kappa \mathrm{B}-$ dependent signaling. Consequently, A20-deficient DCs are hyper-responsive to stimulation, and mice with a specific deletion of A20 in DCs show an accumulation of activated T cells and develop spontaneous autoimmunity. ${ }^{95,96}$ Notably, A20 polymorphisms are also associated with human autoimmune disease,${ }^{94}$ highlighting the physiological relevance of $\mathrm{NF}-\kappa \mathrm{B}$ regulatory pathways for $\mathrm{DC}$ function.

$\mathrm{NF}-\kappa \mathrm{B}$ activation is an important component of DC activation; however, recent data by Ohashi and coworkers suggest that different members of the NF- $\kappa \mathrm{B}$ family of transcription factors have different roles in DC maturation and function. ${ }^{92}$ Using bone marrow-derived DCs and the RIPgp/B6 model (rat insulin promoter expressing glycoprotein of LCMV virus, in C57BL/6 mice) of diabetes they found that $n f k b 1$-deficient DCs promote the differentiation of effector $\mathrm{CD}^{+}{ }^{+}$and $\mathrm{CD}^{+}{ }^{+} \mathrm{T}$ cells that drive autoimmune inflammation in the absence of activation by microbial signals. ${ }^{92}$ These data suggest that the immature/quiescent state of DCs is actively maintained by a specific transcriptional program controlled by $n f k b 1$. However, it is not yet known whether this interpretation model also applies to DCs in vivo.

STAT3. The transcription factor STAT3 mediates the effects of several cytokines that regulate DC differentiation and function. STAT3 participates in the signaling cascade triggered by FLT3L, a molecule important not only for the differentiation of pDCs and cDCs but also for their antiinflammatory effects. ${ }^{97-99}$ In addition, it has been recently shown that a long noncoding RNA targeting STAT3 regulates the activity of mouse and human DCs. ${ }^{100}$ The importance of STAT3 for the regulation of DC function is further highlighted by the effects of STAT3 deficiency. Mice harboring STAT3deficient DCs show enhanced cytokine production following activation, resistance to $\mathrm{IL}-10-$ mediated suppression and increased APC function. ${ }^{101}$ Moreover, naive mice with a specific deficiency of STAT3 in DCs develop spontaneous peribronchial and gut inflammation, suggesting that STAT3dependent signaling controls DC function under homeostatic conditions. In addition, these findings suggest that STAT3 signaling in DCs contributes to the anti-inflammatory effects of other STAT3-activating cytokines, such as IL-27.

Aryl hydrocarbon receptor (AHR). The AHR is a ligandactivated transcription factor that regulates several biological processes, including development ${ }^{102,103}$ and the immune 
response. ${ }^{104}$ The AHR has an important role in the control of the adaptive immune response, through mechanisms that involve the epigenetic remodeling and direct transactivation of target genes. ${ }^{104-113}$ For example, we have found that the AHR controls the differentiation of Tr1 cells in response to IL-27. ${ }^{44,114}$ Recent data suggest that AHR also controls DC activation in vitro and in vivo, affecting the course of CNS inflammation. Although the specific molecular mechanisms involved in the effects of AHR signaling in DCs are mostly unknown, $\mathrm{AHR}$ is known to regulate the activity and degradation of NF- $\kappa \mathrm{B}$ and activator protein $1,{ }^{115,116}$ molecules known to control the response of DCs to stimulation. ${ }^{89,91}$ Regardless of the molecular mechanisms involved, AHR has profound effects on DC function. AHR activation decreases the expression of MHC class II and costimulatory molecules and also the production of Th1- and Th17polarizing cytokines by DCs. ${ }^{41,117-123}$ Indeed, AHR activation boosts the ability of DCs to promote the differentiation and expansion of FoxP3 ${ }^{+}$Tregs. ${ }^{41,118-120}$ These effects involve at least two types of tolerogenic metabolites: (1) Kynurenins. AHR activation upregulates the expression of IDO in DCs, ${ }^{119,120}$ which catalyzes the production of kynurenine. (2) RA. AHR activation in DCs induces the enzymatic machinery that controls the production of RA, ${ }^{112}$ a metabolite that promotes the differentiation of FoxP3 ${ }^{+}$Tregs. $^{124}$ These observations suggest that AHR in DCs constitutes a potential target or therapeutic immunomodulation.

\section{Regulation of DC Function by IL-27}

IL-27 is composed of Ebi3 and IL-27p28. ${ }^{125}$ IL-27 suppresses Th1/Th2 and Th17 responses. ${ }^{126-128}$ In addition, IL-27 promotes the differentiation of Tr1 cells through mechanisms that involve the activation of STAT3- and AHR-dependent signaling. ${ }^{42,44,114,129}$ The anti-inflammatory effects of IL-27 are highlighted by the development of exaggerated Th17 immunity and severe EAE by IL-27 receptor alpha (IL-27R $\alpha$ )-deficient mice. ${ }^{130} \mathrm{IL}-27$ is produced by innate cells in response to TLR activation, by a mechanism that involves the autocrine effects of IFN- $\beta .^{131,132}$ As exogenous IFN- $\beta$ triggers IL-27 production by cells of the innate immune system including $D C s,{ }^{133}$ it has been proposed that the beneficial effects of IFN- $\beta$ treatment in RRMS involve the induction of IL-27 synthesis and its effects on Tr1 and Th17 cell differentiation. ${ }^{77}$ Recent data suggests that, in addition to its activities on $\mathrm{T}$ cells, the immunoregulatory effects of IL-27 involve its effects on DCs.

The receptor for IL-27, constituted by the glycoprotein 130 subunit of the IL- 6 receptor plus a unique IL-27R $\alpha$ chain, ${ }^{134}$ is expressed by $\mathrm{T}$ cells and also by cells of the innate immune system including DCs. ${ }^{135,136}$ However, the role of IL-27 signaling in DCs during CNS autoimmunity is unknown. We recently found increased IL-27R $\alpha$ expression in cDCs than in pDCs. ${ }^{137}$ Moreover, we found that mice carrying IL-27R $\alpha$ deficient DCs develop exacerbated CNS inflammation following EAE induction. The activation of IL-27R signaling in DCs results in a decreased ability to promote the differentiation of effector Th1 and Th17 cells, concomitant with an increased differentiation of $\mathrm{FoxP}_{3}{ }^{+}$Tregs and Tr1 cells in vivo and in vitro. Similar anti-inflammatory effects of IL-27 have been recently reported on pDCs and human DCs. ${ }^{138,139}$
A genome-wide analysis of the effects of IL-27 on DCs found that it modulates $\mathrm{NF}-\kappa \mathrm{B}$ and $\mathrm{A} 20$ signaling and upregulates the expression of molecules with anti-inflammatory activity such as TGF $\beta 1$ and IDO; IL-27 also induces the expression of the ectonucleotidase CD39 (ectonucleoside triphosphate diphosphohydrolase 1) in DCs in a STAT3dependent manner. ${ }^{137}$ Indeed, the anti-inflammatory effects of IL-27 signaling in DCs on EAE were mediated by the upregulation of CD39 and the degradation of extracellular adenosine triphosphate, which activates the NLRP3 (NLR (NOD-like receptor) family, pyrin domain containing 3) inflammasome in DCs ${ }^{137}$ (Figure 3).

\section{Therapeutic Effects of Vaccination with IL-27 Conditioned DCs}

The anti-inflammatory effects of IL-27 on T cells and DCs support its therapeutic use in MS and other autoimmune diseases. IL-27, however, has been reported to act directly on $\mathrm{T}$ cells to boost $\mathrm{CD}^{+}{ }^{+}$T-cell responses, ${ }^{140-144}$ suggesting that IL-27 administration could potentially have undesired detrimental side effects in immune-mediated disorders.

DC vaccination induces immunity to tumors and pathogens ${ }^{145}$ and has been recently approved by the US Food and Drug Administration (FDA) for the treatment of advanced prostate cancer. ${ }^{146}$ Conversely, vaccination with tolerogenic DCs induces antigen-specific tolerance. ${ }^{147,148}$ Thus, based on the tolerogenic effects of IL-27 signaling in DCs, and to avoid the potential pathogenic effects of IL-27 administration, we investigated the therapeutic effects of vaccination with IL27-conditioned DCs on EAE. We found that IL-27 conditioned DCs loaded with myelin antigens arrest CNS inflammation and $E A E$ development in preventive and therapeutic paradigms in a CD39-dependent manner. ${ }^{137}$ Interestingly, DC vaccination with IL-27-conditioned DCs arrests the immune response directed against the antigen use to induce EAE and also the subsequent spreading of the immune response against additional CNS antigens as measured with antigen arrays. ${ }^{110,149,150}$ Taken together, these data demonstrate that IL-27 signaling in DCs limits inflammation in the CNS through CD39-dependent mechanisms. It is still unknown, however, whether this immunoregulatory axis is relevant for the regulation of inflammation in other tissues and whether CD39 is involved in the anti-inflammatory effects of other STAT3-activating cytokines that act on DCs, such as IL-10.

\section{Nanoparticles (NPs) for the Induction of Antigen- Specific Tolerance}

Our DC vaccination experiments suggested that IL-27 signaling in DCs might provide targets for the therapeutic modulation of the immune response. However, the use of cell-based therapies in the clinical practice is limited by the logistical issues associated with the preparation of DC vaccines from each patient under highly controlled conditions.

In order to address these limitations, we investigated the signaling pathways controlled by IL-27 in DCs. Our transcriptional analysis identified AHR as a potential mediator of the modulatory effects of IL-27 in DCs. ${ }^{137}$ Indeed, this finding is 


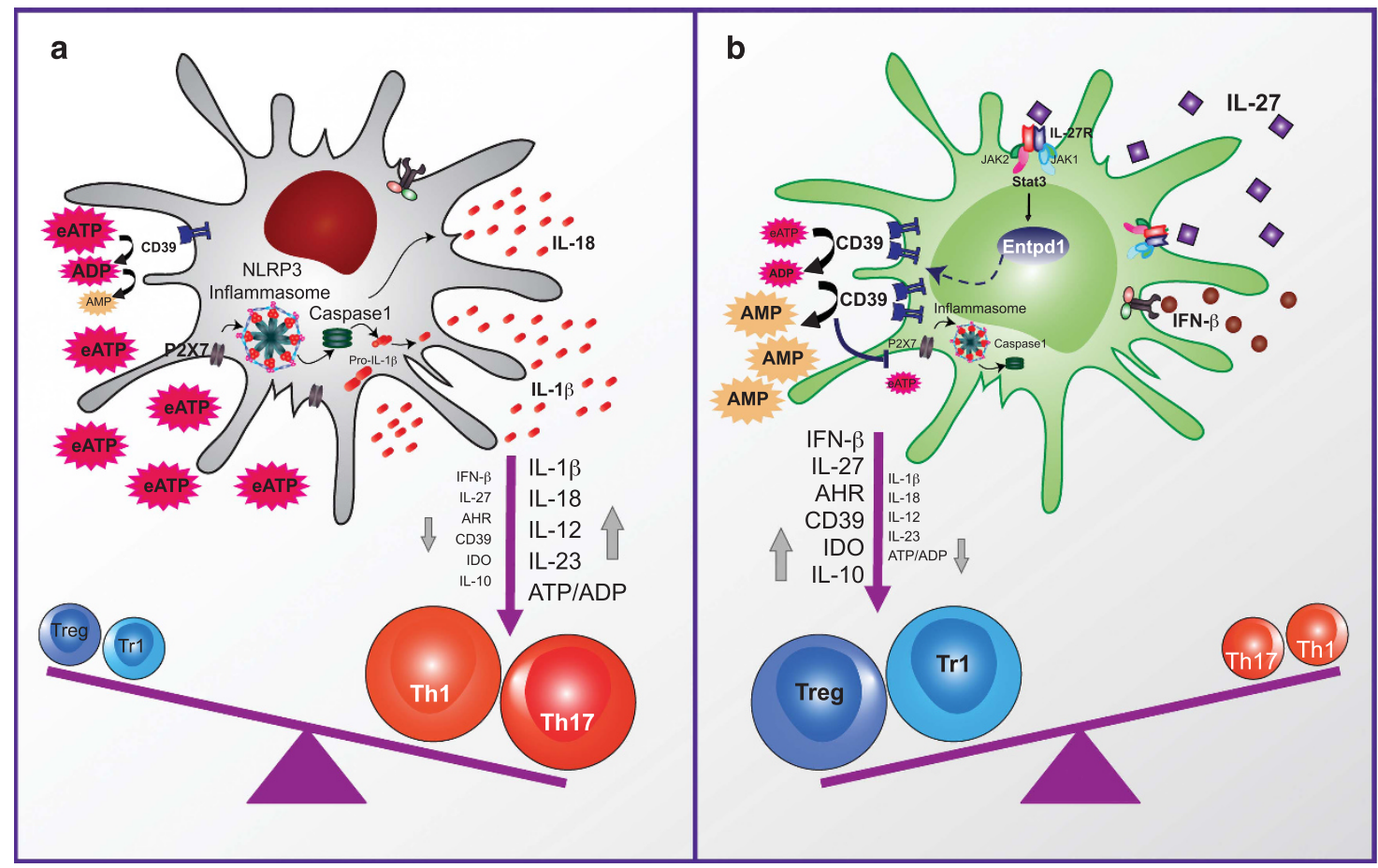

Figure 3 IL-27 acts on DCs to control Treg and Teff differentiation via ENTPD1 (CD39) upregulation. (a) Extracellular ATP (eATP) activates the NLRP3 inflammasome in DCs and promotes the differentiation of effector T cells. (b) ENTPD1 (CD39) induced by IL-27 in a STAT3-dependent manner degrades eATP, limits effector T-cell differentiation and promotes the generation of regulatory $T$ cells

not surprising, because AHR also mediates the effects of IL-27 in T cells during Tr1 differentiation. ${ }^{44,114}$

The broad expression pattern of AHR, however, constitutes a challenge for the therapeutic exploitation of its immunomodulatory effects. However, recent developments in nanotechnology provide new approaches for the cell-specific delivery of one or several compounds in vivo. ${ }^{151}$ Based on the tolerogenic effects of AHR activation in DCs, we engineered NPs to co-deliver the endogenous non-toxic AHR ligand 2-(1'H-indole-3'-carbonyl)-thiazole-4-carboxylic acid methyl ester (ITE) together with myelin-specific antigens to APCs in vivo ${ }^{113}$ (Figure 4).

We found that ITE-loaded NPs activate AHR signaling in DCs, inducing a tolerogenic phenotype characterized by the reduced ability to generate Th1 and Th17 cells, and an increased ability to promote $\mathrm{FoxP}^{+}$Treg differentiation in vitro and in vivo. ${ }^{113}$ Accordingly, NPs loaded with ITE and myelin antigens suppress the development of EAE both in preventive and therapeutic paradigms. These effects were mediated by the activation of AHR signaling in DCs, because they were not observed in mice carrying a specific deletion of AHR in DCs. Taken together, these data show that the activation of tolerogenic signaling pathways in DCs with NPs offers a new avenue for the selective regulation of the immune response in immune-mediated disorders. ${ }^{108}$

\section{Conclusion and Future Directions}

Considering the central role of DCs in the regulation of the immune response, it is important to identify the molecular pathways that regulate their activity, because these pathways might provide new targets for therapeutic immunomodulation. Furthermore, candidate pathways should be examined in DCs from patients affected by immune-mediated disorders, to determine their relevance for the regulation of human DCs and also their potential to revert DC abnormalities associated with disease pathology.

A related issue is whether tolerogenic DC lineages exist or whether they represent alternative stages of DC maturation or activation. The analysis of transcriptional programs associated with tolerogenic DCs will certainly address this point and provide additional tools for their characterization and manipulation.

Finally, it is important to develop methods for the efficient generation of immunogenic or tolerogenic DCs that can be implemented in a clinical setup for the treatment of human diseases by DC vaccination. The approval by the FDA of DC vaccination as a therapy for prostate cancer is an encouraging step, but much more has to be done to efficiently translate these findings to the clinic. An alternative to this approach is the development of NP-based strategies for the specific modulation of signaling pathways in DCs. However, these approaches have to be optimized to include the production of biocompatible materials in large scale and also to reach specific DC populations in the periphery and target organs. Nevertheless, considering the recent advances in our understanding of DC function and regulation in autoimmunity, a new generation of DC-based immunomodulators can be envisioned in the near future for the therapeutic manipulation of antigen-specific immunity. 


\section{$\triangle$ ITE \\ Antigen PEG}

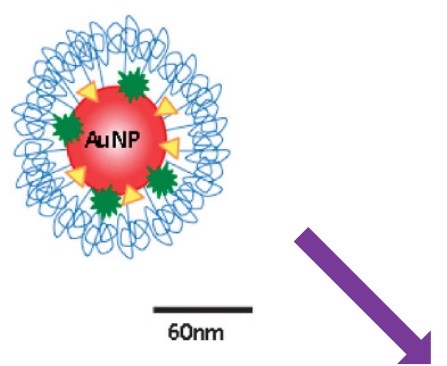

Control of autoimmunity

Figure 4 Nanoparticles for drug delivery and induction of antigen-specific tolerance. NPs are engineered to co-delivery the non-toxic AHR ligand ITE and the myelinspecific antigen $\mathrm{MOG}_{35-55}$ to DCs. Targeting of AHR in DCs induces a tolerogenic phenotype and the ability to promote the generation of antigen-specific FoxP3 ${ }^{+}$Tregs in vitro and in vivo that suppress the encephalitogenic T-cell response (Th1 and Th17)

\section{Conflict of Interest}

The authors declare no conflict of interest.

Acknowledgements. The author apologizes to many colleagues whose work could not be cited because of space limitations. Research in the Quintana laboratory has been supported by the National Institutes of Health, the National Multiple Sclerosis Society and the Juvenile Diabetes Research Foundation.

1. Steinman RM. Decisions about dendritic cells: past, present, and future. Annu Rev Immunol 2012; 30: 1-22.

2. Mildner A, Jung S. Development and function of dendritic cell subsets. Immunity 2014; 40: $642-656$.

3. Reizis B. Regulation of plasmacytoid dendritic cell development. Curr Opin Immunol 2010; 22: 206-211.

4. Satpathy AT, Wu X, Albring JC, Murphy KM. Re(de)fining the dendritic cell lineage. Nat Immunol 2012; 13: 1145-1154.

5. Becker AM, Michael DG, Satpathy AT, Sciammas R, Singh H, Bhattacharya D. IRF-8 extinguishes neutrophil production and promotes dendritic cell lineage commitment in both myeloid and lymphoid mouse progenitors. Blood 2012; 119: 2003-2012.

6. Schiavoni G, Mattei F, Sestili P, Borghi P, Venditti M, Morse HC 3rd et al. ICSBP is essential for the development of mouse type I interferon-producing cells and for the generation and activation of CD8alpha $(+)$ dendritic cells. J Exp Med 2002; 196 1415-1425.

7. Liu K, Waskow C, Liu X, Yao K, Hoh J, Nussenzweig M. Origin of dendritic cells in peripheral lymphoid organs of mice. Nat Immunol 2007; 8: 578-583.

8. Meredith MM, Liu K, Darrasse-Jeze G, Kamphorst AO, Schreiber HA, Guermonprez P et al. Expression of the zinc finger transcription factor $\mathrm{ZDC}(\mathrm{Zbtb} 46, \mathrm{Btbd} 4)$ defines the classical dendritic cell lineage. J Exp Med 2012; 209: 1153-1165.

9. Satpathy AT, Kc W, Albring JC, Edelson BT, Kretzer NM, Bhattacharya D et al. Zbtb46 expression distinguishes classical dendritic cells and their committed progenitors from other immune lineages. J Exp Med 2012; 209: 1135-1152.

10. Burkly L, Hession C, Ogata L, Reilly C, Marconi LA, Olson D et al. Expression of relB is required for the development of thymic medulla and dendritic cells. Nature 1995; 373 531-536.

11. Ontsuka H, Sakamoto A, Pan J, Inage S, Horigome S, Ichii H et al. Bcl6 is required for the development of mouse CD4 + and CD8alpha + dendritic cells. J Immunol 2011; 186: 255-263.
12. Suzuki S, Honma K, Matsuyama T, Suzuki K, Toriyama K, Akitoyo I et al. Critical roles of interferon regulatory factor 4 in CD11bhighCD8alpha- dendritic cell development. Proc Natl Acad Sci USA 2004; 101: 8981-8986.

13. Wu L, D'Amico A, Winkel KD, Suter M, Lo D, Shortman K. RelB is essential for the development of myeloid-related CD8alpha - dendritic cells but not of lymphoid-related CD8alpha + dendritic cells. Immunity 1998; 9: 839-847.

14. Satpathy AT, Murphy KM, Kc W. Transcription factor networks in dendritic cell development. Semin Immunol 2011; 23: 388-397.

15. Hacker C, Kirsch RD, Ju XS, Hieronymus T, Gust TC, Kuhl C et al. Transcriptional profiling identifies Id2 function in dendritic cell development. Nat Immunol 2003; 4: 380-386.

16. Hildner K, Edelson BT, Purtha WE, Diamond M, Matsushita H, Kohyama M et al. Batf3 deficiency reveals a critical role for CD8alpha + dendritic cells in cytotoxic $T$ cell immunity. Science 2008; 322: 1097-1100.

17. Tussiwand R, Lee WL, Murphy TL, Mashayekhi M, Kc W, Albring JC et al. Compensatory dendritic cell development mediated by BATF-IRF interactions. Nature 2012; 490: 502-507.

18. Park CS, Lee PH, Yamada T, Burns A, Shen Y, Puppi M et al. Kruppel-like factor 4 (KLF4) promotes the survival of natural killer cells and maintains the number of conventional dendritic cells in the spleen. J Leukoc Biol 2012; 91: 739-750.

19. Reizis B, Bunin A, Ghosh HS, Lewis KL, Sisirak V. Plasmacytoid dendritic cells: recent progress and open questions. Annu Rev Immunol 2011; 29: 163-183.

20. Naik SH, Sathe P, Park HY, Metcalf D, Proietto Al, Dakic A et al. Development of plasmacytoid and conventional dendritic cell subtypes from single precursor cells derived in vitro and in vivo. Nat Immunol 2007; 8: 1217-1226.

21. Onai N, Obata-Onai A, Schmid MA, Ohteki T, Jarrossay D, Manz MG. Identification of clonogenic common Flt3 + M-CSFR + plasmacytoid and conventional dendritic cell progenitors in mouse bone marrow. Nat Immunol 2007; 8: 1207-1216.

22. Cisse B, Caton ML, Lehner M, Maeda T, Scheu S, Locksley R et al. Transcription factor $\mathrm{E} 2-2$ is an essential and specific regulator of plasmacytoid dendritic cell development. Cell 2008; 135: 37-48.

23. Ghosh HS, Cisse B, Bunin A, Lewis KL, Reizis B. Continuous expression of the transcription factor e2-2 maintains the cell fate of mature plasmacytoid dendritic cells. Immunity 2010; 33: 905-916.

24. Schotte R, Nagasawa M, Weijer K, Spits H, Blom B. The ETS transcription factor Spi-B is required for human plasmacytoid dendritic cell development. J Exp Med 2004; 200: 1503-1509.

25. Anderson MS, Venanzi ES, Klein L, Chen Z, Berzins SP, Turley SJ et al. Projection of an immunological self shadow within the thymus by the AIRE protein. Science 2002; 298: 1395-1401. 
26. Mor F, Boccaccio GL, Unger T. Expression of autoimmune disease-related antigens by cells of the immune system. J Neurosci Res 1998; 54: 254-262.

27. Peterson $\mathrm{P}, \mathrm{Org} \mathrm{T}$, Rebane A. Transcriptional regulation by AIRE: molecular mechanisms of central tolerance. Nat Rev Immunol 2008; 8: 948-957.

28. Aschenbrenner K, D'Cruz LM, Vollmann EH, Hinterberger M, Emmerich J, Swee LK et al. Selection of Foxp3 + regulatory $T$ cells specific for self antigen expressed and presented by Aire + medullary thymic epithelial cells. Nat Immunol 2007; 8: 351-358.

29. Nomura T, Sakaguchi S. Foxp3 and Aire in thymus-generated Treg cells: a link in selftolerance. Nat Immunol 2007; 8: 333-334.

30. Gallegos AM, Bevan MJ. Central tolerance to tissue-specific antigens mediated by direct and indirect antigen presentation. J Exp Med 2004; 200: 1039-1049.

31. Hubert FX, Kinkel SA, Davey GM, Phipson B, Mueller SN, Liston A et al. Aire regulates the transfer of antigen from mTECs to dendritic cells for induction of thymic tolerance. Blood 2011; 118: 2462-2472

32. Bonasio R, Scimone ML, Schaerli P, Grabie N, Lichtman AH, von Andrian UH. Clonal deletion of thymocytes by circulating dendritic cells homing to the thymus. Nat Immunol 2006; 7: 1092-1100.

33. Proietto Al, van Dommelen S, Zhou P, Rizzitelli A, D'Amico A, Steptoe RJ et al. Dendritic cells in the thymus contribute to T-regulatory cell induction. Proc Natl Acad Sci USA 2008; 105: 19869-19874.

34. Birnberg T, Bar-On L, Sapoznikov A, Caton ML, Cervantes-Barragan L, Makia D et al. Lack of conventional dendritic cells is compatible with normal development and T cell homeostasis, but causes myeloid proliferative syndrome. Immunity 2008; 29: 986-997.

35. Hawiger D, Inaba K, Dorsett Y, Guo M, Mahnke K, Rivera M et al. Dendritic cells induce peripheral T cell unresponsiveness under steady state conditions in vivo. $J$ Exp Med 2001; 194: 769-779.

36. Hawiger D, Masilamani RF, Bettelli E, Kuchroo VK, Nussenzweig MC. Immunological unresponsiveness characterized by increased expression of CD5 on peripheral T cells induced by dendritic cells in vivo. Immunity 2004; 20: 695-705.

37. Probst HC, McCoy K, Okazaki T, Honjo T, van den Broek M. Resting dendritic cells induce peripheral CD8 + T cell tolerance through PD-1 and CTLA-4. Nat Immunol 2005; 6: 280-286.

38. Coombes JL, Siddiqui KR, Arancibia-Carcamo CV, Hall J, Sun CM, Belkaid Y et al. A functionally specialized population of mucosal CD103 + DCs induces Foxp3 + regulatory T cells via a TGF-beta and retinoic acid-dependent mechanism. J Exp Med 2007; 204: 1757-1764.

39. Grohmann U, Fallarino F, Puccetti P. Tolerance, DCs and tryptophan: much ado about IDO. Trends Immunol 2003; 24: 242-248.

40. Sun CM, Hall JA, Blank RB, Bouladoux N, Oukka M, Mora JR et al. Small intestine lamina propria dendritic cells promote de novo generation of Foxp3 T reg cells via retinoic acid. J Exp Med 2007; 204: 1775-1785.

41. Quintana FJ, Murugaiyan G, Farez MF, Mitsdoerffer M, Tukpah AM, Burns EJ et al. An endogenous aryl hydrocarbon receptor ligand acts on dendritic cells and $T$ cells to suppress experimental autoimmune encephalomyelitis. Proc Natl Acad Sci USA 2010; 107: 20768-20773.

42. Awasthi A, Carrier Y, Peron JP, Bettelli E, Kamanaka M, Flavell RA et al. A dominant function for interleukin 27 in generating interleukin 10-producing anti-inflammatory $T$ cells. Nat Immunol 2007; 8: 1380-1389.

43. Wakkach A, Fournier N, Brun V, Breittmayer JP, Cottrez F, Groux H. Characterization of dendritic cells that induce tolerance and T regulatory 1 cell differentiation in vivo. Immunity 2003; 18: 605-617.

44. Wu HY, Quintana FJ, da Cunha AP, Dake BT, Koeglsperger T, Starossom SC et al. In vivo induction of Tr1 cells via mucosal dendritic cells and AHR signaling. PLoS One 2011; 6: e23618.

45. Bar-On L, Birnberg T, Kim KW, Jung S. Dendritic cell-restricted CD80/86 deficiency results in peripheral regulatory $\mathrm{T}$-cell reduction but is not associated with lymphocyte hyperactivation. Eur J Immunol 2011; 41: 291-298.

46. Yogev N, Frommer F, Lukas D, Kautz-Neu K, Karram K, lelo D et al. Dendritic cells ameliorate autoimmunity in the CNS by controlling the homeostasis of PD-1 receptor $(+)$ regulatory T cells. Immunity 2012; 37: 264-275.

47. Hopp AK, Rupp A, Lukacs-Kornek V. Self-antigen presentation by dendritic cells in autoimmunity. Front Immunol 2014; 5: 55.

48. Johnson DJ, Ohashi PS. Molecular programming of steady-state dendritic cells: impact on autoimmunity and tumor immune surveillance. Ann NY Acad Sci 2013; 1284: 46-51.

49. Kim SJ, Diamond B. Modulation of tolerogenic dendritic cells and autoimmunity. Semin Cell Dev Biol 2014; e-pub ahead of print 18 April 2014; doi:10.1016/ j.semcdb.2014.04.020

50. Wu GF, Shindler KS, Allenspach EJ, Stephen TL, Thomas HL, Mikesell RJ et al. Limited sufficiency of antigen presentation by dendritic cells in models of central nervous system autoimmunity. J Autoimmun 2011; 36: 56-64.

51. Huang G, Wang Y, Vogel P, Kanneganti TD, Otsu K, Chi H. Signaling via the kinase p38alpha programs dendritic cells to drive $\mathrm{TH} 17$ differentiation and autoimmune inflammation. Nat Immunol 2012; 13: 152-161.
52. Greter M, Heppner FL, Lemos MP, Odermatt BM, Goebels N, Laufer T et al. Dendritic cells permit immune invasion of the CNS in an animal model of multiple sclerosis. Nat Med 2005; 11: 328-334.

53. Lehmann PV, Forsthuber T, Miller A, Sercarz EE. Spreading of T-cell autoimmunity to cryptic determinants of an autoantigen. Nature 1992; 358: 155-157.

54. Mcmahon EJ, Bailey SL, Castenada CV, Waldner H, Miller SD. Epitope spreading initiates in the CNS in two mouse models of multiple sclerosis. Nat Med 2005; 11: 335-339.

55. Bailey-Bucktrout SL, Caulkins SC, Goings G, Fischer JA, Dzionek A, Miller SD. Cutting edge: central nervous system plasmacytoid dendritic cells regulate the severity of relapsing experimental autoimmune encephalomyelitis. J Immunol 2008; 180: 6457-6461.

56. Weiner $\mathrm{HL}$. The challenge of multiple sclerosis: how do we cure a chronic heterogeneous disease? Ann Neurol 2009; 65: 239-248.

57. Nylander A, Hafler DA. Multiple sclerosis. J Clin Invest 2012; 122: 1180-1188.

58. Lande R, Gafa V, Serafini B, Giacomini E, Visconti A, Remoli ME et al. Plasmacytoid dendritic cells in multiple sclerosis: intracerebral recruitment and impaired maturation in response to interferon-beta. J Neuropathol Exp Neurol 2008; 67: 388-401.

59. Longhini AL, von Glehn F, Brandao CO, de Paula RF, Pradella F, Moraes AS et al. Plasmacytoid dendritic cells are increased in cerebrospinal fluid of untreated patients during multiple sclerosis relapse. J Neuroinflammation 2011; 8: 2.

60. Karni A, Abraham M, Monsonego A, Cai G, Freeman GJ, Hafler D et al. Innate immunity in multiple sclerosis: myeloid dendritic cells in secondary progressive multiple sclerosis are activated and drive a proinflammatory immune response. J Immunol 2006; 177: 4196-4202.

61. Vaknin-Dembinsky A, Balashov K, Weiner HL. IL-23 is increased in dendritic cells in multiple sclerosis and down-regulation of IL-23 by antisense oligos increases dendritic cell IL-10 production. J Immunol 2006; 176: 7768-7774.

62. Vaknin-Dembinsky A, Murugaiyan G, Hafler DA, Astier AL, Weiner HL. Increased IL-23 secretion and altered chemokine production by dendritic cells upon CD46 activation in patients with multiple sclerosis. J Neuroimmunol 2008; 195: 140-145.

63. Pashenkov M, Huang YM, Kostulas V, Haglund M, Soderstrom M, Link H. Two subsets of dendritic cells are present in human cerebrospinal fluid. Brain 2001; 124(Pt 3): 480-492.

64. Pashenkov M, Teleshova N, Kouwenhoven M, Kostulas V, Huang YM, Soderstrom M et al. Elevated expression of CCR5 by myeloid (CD11C + ) blood dendritic cells in multiple sclerosis and acute optic neuritis. Clin Exp Immunol 2002; 127: 519-526.

65. Boven LA, Montagne L, Nottet HS, De Groot CJ. Macrophage inflammatory protein1alpha (MIP-1alpha), MIP-1beta, and RANTES mRNA semiquantification and protein expression in active demyelinating multiple sclerosis (MS) lesions. Clin Exp Immunol 2000; 122: 257-263.

66. Barcellos LF, Schito AM, Rimmler JB, Vittinghoff E, Shih A, Lincoln R et al. CC-chemokine receptor 5 polymorphism and age of onset in familial multiple sclerosis. Multiple Sclerosis Genetics Group. Immunogenetics 2000; 51: 281-288.

67. Gade-Andavolu R, Comings DE, MacMurray J, Rostamkhani M, Cheng LS, Tourtellotte WW et al. Association of CCR5 delta32 deletion with early death in multiple sclerosis. Genet Med 2004; 6: 126-131.

68. Stasiolek M, Bayas A, Kruse N, Wieczarkowiecz A, Toyka KV, Gold R et al. Impaired maturation and altered regulatory function of plasmacytoid dendritic cells in multiple sclerosis. Brain 2006; 129(Pt 5): 1293-1305.

69. Nuyts AH, Lee WP, Bashir-Dar R, Berneman ZN, Cools N. Dendritic cells in multiple sclerosis: key players in the immunopathogenesis, key players for new cellular immunotherapies? Mult Scler 2013; 19: 995-1002.

70. Brendecke SM, Prinz M. How type I interferons shape myeloid cell function in CNS autoimmunity. J Leukoc Biol 2012; 92: 479-488.

71. Kalinke U, Prinz M. Endogenous, or therapeutically induced, type I interferon responses differentially modulate Th1/Th17-mediated autoimmunity in the CNS. Immunol Cell Biol 2012; 90: 505-509.

72. Prinz M, Knobeloch KP. Type I interferons as ambiguous modulators of chronic inflammation in the central nervous system. Front Immunol 2012; 3: 67.

73. Axtell RC, de Jong BA, Boniface K, van der Voort LF, Bhat R, De Sarno P et al. T helper type 1 and 17 cells determine efficacy of interferon-beta in multiple sclerosis and experimental encephalomyelitis. Nat Med 2010; 16: 406-412.

74. Dann A, Poeck H, Croxford AL, Gaupp S, Kierdorf K, Knust M et al. Cytosolic RIG-I-like helicases act as negative regulators of sterile inflammation in the CNS. Nat Neurosci 2012; 15: 98-106.

75. Shinohara ML, Kim JH, Garcia VA, Cantor H. Engagement of the type I interferon receptor on dendritic cells inhibits $T$ helper 17 cell development: role of intracellular osteopontin. Immunity 2008; 29: 68-78.

76. Hirotani M, Niino M, Fukazawa T, Yaguchi H, Nakamura M, Kikuchi S et al. Decreased interferon-alpha production in response to $\mathrm{CpG}$ DNA dysregulates cytokine responses in patients with multiple sclerosis. Clin Immunol 2012; 143: 145-151.

77. Mitsdoerffer M, Kuchroo V. New pieces in the puzzle: how does interferon-beta really work in multiple sclerosis? Ann Neurol 2009; 65: 487-488.

78. Hussien Y, Sanna A, Soderstrom M, Link H, Huang YM. Glatiramer acetate and IFN-beta act on dendritic cells in multiple sclerosis. J Neuroimmunol 2001; 121: 102-110. 
79. Hussien Y, Sanna A, Soderstrom M, Link H, Huang YM. Multiple sclerosis: expression of CD1a and production of IL-12p70 and IFN-gamma by blood mononuclear cells in patients on combination therapy with IFN-beta and glatiramer acetate compared to monotherapy with IFN-beta. Mult Scler 2004; 10: 16-25.

80. Sellebjerg F, Hesse D, Limborg S, Lund H, Sondergaard HB, Krakauer M et al. Dendritic cell, monocyte and $\mathrm{T}$ cell activation and response to glatiramer acetate in multiple sclerosis. Mult Scler 2013; 19: 179-187.

81. Vieira PL, Heystek HC, Wormmeester J, Wierenga EA, Kapsenberg ML. Glatiramer acetate (copolymer-1, copaxone) promotes Th2 cell development and increased IL-10 production through modulation of dendritic cells. J Immunol 2003; 170: 4483-4488.

82. Weber MS, Prod'homme T, Youssef S, Dunn SE, Rundle CD, Lee L et al. Type II monocytes modulate $T$ cell-mediated central nervous system autoimmune disease. Nat Med 2007; 13: 935-943.

83. Bruck W, Vollmer T. Multiple sclerosis: oral laquinimod for MS-bringing the brain into focus. Nat Rev Neurol 2013; 9: 664-665.

84. Comi G, Jeffery D, Kappos L, Montalban X, Boyko A, Rocca MA et al. Placebo-controlled trial of oral laquinimod for multiple sclerosis. N Engl J Med 2012; 366: 1000-1009.

85. Filippi M, Rocca MA, Pagani E, De Stefano N, Jeffery D, Kappos L et al. Placebo-controlled trial of oral laquinimod in multiple sclerosis: MRI evidence of an effect on brain tissue damage. J Neurol Neurosurg Psychiatry 2013; 85: 851-858.

86. Vollmer TL, Sorensen PS, Selmaj K, Zipp F, Havrdova E, Cohen JA et al. A randomized placebo-controlled phase III trial of oral laquinimod for multiple sclerosis. J Neurol 2014 261: 773-783.

87. Jolivel V, Luessi F, Masri J, Kraus SH, Hubo M, Poisa-Beiro L et al. Modulation of dendritic cell properties by laquinimod as a mechanism for modulating multiple sclerosis Brain 2013; 136(Pt 4): 1048-1066.

88. Schulze-Topphoff U, Shetty A, Varrin-Doyer M, Molnarfi N, Sagan SA, Sobel RA et al. Laquinimod, a quinoline-3-carboxamide, induces type II myeloid cells that modulate central nervous system autoimmunity. PLoS One 2012; 7: e33797.

89. Garber M, Yosef N, Goren A, Raychowdhury R, Thielke A, Guttman M et al. A high-throughput chromatin immunoprecipitation approach reveals principles of dynamic gene regulation in mammals. Mol Cell 2012; 47: 810-822.

90. Paul F, Amit I. Plasticity in the transcriptional and epigenetic circuits regulating dendritic cell lineage specification and function. Curr Opin Immunol 2014; 30C: 1-8.

91. Amit I, Garber M, Chevrier N, Leite AP, Donner Y, Eisenhaure T et al. Unbiased reconstruction of a mammalian transcriptional network mediating pathogen responses. Science 2009; 326: 257-263

92. Dissanayake D, Hall H, Berg-Brown N, Elford AR, Hamilton SR, Murakami K et al. Nuclear factor-kappaB1 controls the functional maturation of dendritic cells and prevents the activation of autoreactive T cells. Nat Med 2011; 17: 1663-1667.

93. Shih VF, Davis-Turak J, Macal M, Huang JQ, Ponomarenko J, Kearns JD et al. Control of RelB during dendritic cell activation integrates canonical and noncanonical NF-kappaB pathways. Nat Immunol 2012; 13: 1162-1170.

94. Ma A, Malynn BA. A20: linking a complex regulator of ubiquitylation to immunity and human disease. Nat Rev Immunol 2012; 12: 774-785.

95. Hammer GE, Turer EE, Taylor KE, Fang CJ, Advincula R, Oshima S et al. Expression of A20 by dendritic cells preserves immune homeostasis and prevents colitis and spondyloarthritis. Nat Immunol 2011; 12: 1184-1193.

96. Kool M, van Loo G, Waelput W, De Prijck S, Muskens F, Sze M et al. The ubiquitin-editing protein A20 prevents dendritic cell activation, recognition of apoptotic cells, and systemic autoimmunity. Immunity 2011; 35: 82-96.

97. Collins $\mathrm{CB}$, Aherne CM, McNamee EN, Lebsack MD, Eltzschig $\mathrm{H}$, Jedlicka $\mathrm{P}$ et al. Flt3 ligand expands CD103 $(+)$ dendritic cells and FoxP3 $(+)$ T regulatory cells, and attenuates Crohn's-like murine ileitis. Gut 2012; 61: 1154-1162.

98. Darrasse-Jeze G, Deroubaix S, Mouquet H, Victora GD, Eisenreich T, Yao KH et al. Feedback control of regulatory $\mathrm{T}$ cell homeostasis by dendritic cells in vivo. J Exp Med 2009; 206: 1853-1862.

99. Swee LK, Bosco N, Malissen B, Ceredig R, Rolink A. Expansion of peripheral naturally occurring T regulatory cells by Fms-like tyrosine kinase 3 ligand treatment. Blood 2009 113: 6277-6287.

100. Wang $P$, Xue Y, Han Y, Lin L, Wu C, Xu S et al. The STAT3-binding long noncoding RNA Inc-DC controls human dendritic cell differentiation. Science 2014; 344: 310-313.

101. Melillo JA, Song L, Bhagat G, Blazquez AB, Plumlee CR, Lee $C$ et al. Dendritic cell (DC)-specific targeting reveals Stat3 as a negative regulator of DC function. $J$ Immunol 2010; 184: 2638-2645.

102. Gasiewicz TA, Henry EC, Collins LL. Expression and activity of aryl hydrocarbon receptors in development and cancer. Crit Rev Eukaryot Gene Expr 2008; 18: 279-321.

103. Hillegass JM, Murphy KA, Villano CM, White LA. The impact of aryl hydrocarbon recepto signaling on matrix metabolism: implications for development and disease. Biol Chem 2006; 387: 1159-1173.

104. Quintana FJ, Sherr DH. Aryl hydrocarbon receptor control of adaptive immunity. Pharmacol Rev 2013; 65: 1148-1161.

105. Mascanfroni ID, Yeste A, Vieira SM, Burns EJ, Patel B, Sloma I et al. IL-27 acts on DCs to suppress the $T$ cell response and autoimmunity by inducing expression of the immunoregulatory molecule CD39. Nat Immunol 2013; 14: 1054-1063.

106. Quintana FJ. The aryl hydrocarbon receptor: A molecular pathway for the environmental control of the immune response. Immunology 2012; 138: 183-189.
107. Quintana FJ. Regulation of central nervous system autoimmunity by the aryl hydrocarbon receptor. Semin Immunopathol 2013; 35: 627-635.

108. Quintana FJ. Nanoparticles for the induction of antigen-specific Tregs. Immunotherapy 2013: 5: 437-440.

109. Quintana FJ, Basso AS, Iglesias AH, Korn T, Farez MF, Bettelli E et al. Control of T(reg) and $T(H) 17$ cell differentiation by the aryl hydrocarbon receptor. Nature 2008; 453: $65-71$

110. Quintana FJ, Farez MF, Viglietta V, Iglesias AH, Merbl $Y$, Izquierdo $G$ et al. Antigen microarrays identify unique serum autoantibody signatures in clinical and pathologic subtypes of multiple sclerosis. Proc Natl Acad Sci USA 2008; 105: 18889-18894

111. Quintana FJ, Jin H, Burns EJ, Nadeau M, Yeste A, Kumar D et al. Aiolos promotes $T(H) 17$ differentiation by directly silencing II2 expression. Nat Immunol 2012; 13: 770-777.

112. Gandhi R, Kumar D, Burns EJ, Nadeau M, Dake B, Laroni A et al. Activation of the aryl hydrocarbon receptor induces human type 1 regulatory $T$ cell-like and Foxp3 $(+)$ regulatory T cells. Nature Immunology 2010; 11: 846-853.

113. Yeste A, Nadeau M, Burns EJ, Weiner HL, Quintana FJ. Nanoparticle-mediated codelivery of myelin antigen and a tolerogenic small molecule suppresses experimental autoimmune encephalomyelitis. Proc Natl Acad Sci USA 2012; 109: 11270-11275.

114. Apetoh L, Quintana FJ, Pot C, Joller N, Xiao S, Kumar D et al. The aryl hydrocarbon receptor interacts with $\mathrm{c}$-Maf to promote the differentiation of type 1 regulatory $\mathrm{T}$ cells induced by IL-27. Nat Immunol 2010; 11: 854-861.

115. Gillesby BE, Stanostefano M, Porter W, Safe S, Wu ZF, Zacharewski TR. Identification of a motif within the 5 ' regulatory region of pS2 which is responsible for AP-1 binding and TCDD-mediated suppression. Biochemistry 1997; 36: 6080-6089.

116. Tian $Y$, Ke S, Denison MS, Rabson AB, Gallo MA. Ah receptor and NF-kappaB interactions, a potential mechanism for dioxin toxicity. J Biol Chem 1999; 274: 510-515.

117. Benson JM, Shepherd DM. Dietary ligands of the aryl hydrocarbon receptor induce anti-inflammatory and immunoregulatory effects on murine dendritic cells. Toxicol Sci 2011; 124: 327-338.

118. Hauben E, Gregori S, Draghici E, Migliavacca B, Olivieri S, Woisetschlager M et al. Activation of the aryl hydrocarbon receptor promotes allograft-specific tolerance through direct and dendritic cell-mediated effects on regulatory T cells. Blood 2008; 112: 1214-1222.

119. Mezrich JD, Fechner JH, Zhang X, Johnson BP, Burlingham WJ, Bradfield CA. An interaction between kynurenine and the aryl hydrocarbon receptor can generate regulatory T cells. J Immunol 2010; 185: 3190-3198.

120. Nguyen NT, Kimura A, Nakahama T, Chinen I, Masuda K, Nohara $K$ et al. Aryl hydrocarbon receptor negatively regulates dendritic cell immunogenicity via a kynurenine-dependent mechanism. Proc Natl Acad Sci USA 2010; 107: 19961-19966.

121. Simones T, Shepherd DM. Consequences of AHR activation in steady-state dendritic cells. Toxicol Sci 2011; 119: 293-307.

122. Vogel CF, Goth SR, Dong B, Pessah IN, Matsumura F. Aryl hydrocarbon receptor signaling mediates expression of indoleamine 2,3-dioxygenase. Biochem Biophys Res Commun 2008; 375: 331-335.

123. Wang HK, Yeh $\mathrm{CH}$, Iwamoto $\mathrm{T}$, Satsu $\mathrm{H}$, Shimizu M, Totsuka M. Dietary flavonoid naringenin induces regulatory $T$ cells via an aryl hydrocarbon receptor mediated pathway. J Agric Food Chem 2012; 60: 2171-2178.

124. Hall JA, Grainger JR, Spencer SP, Belkaid $Y$. The role of retinoic acid in tolerance and immunity. Immunity 2011; 35: 13-22.

125. Kastelein RA, Hunter CA, Cua DJ. Discovery and biology of IL-23 and IL-27: related but functionally distinct regulators of inflammation. Annu Rev Immunol 2007; 25: 221-242.

126. Yoshimoto T, Yasuda K, Mizuguchi J, Nakanishi K. IL-27 suppresses Th2 cell development and Th2 cytokines production from polarized Th2 cells: a novel therapeutic way for Th2-mediated allergic inflammation. J Immunol 2007; 179: 4415-4423.

127. Rosas LE, Satoskar AA, Roth KM, Keiser TL, Barbi J, Hunter C et al. Interleukin-27R (WSX-1/T-cell cytokine receptor) gene-deficient mice display enhanced resistance to leishmania donovani infection but develop severe liver immunopathology. Am J Pathol 2006; 168: 158-169.

128. Stumhofer JS, Laurence A, Wilson EH, Huang E, Tato CM, Johnson LM et al. Interleukin 27 negatively regulates the development of interleukin 17-producing $T$ helper cells during chronic inflammation of the central nervous system. Nat Immunol 2006; 7: 937-945

129. Stumhofer JS, Silver JS, Laurence A, Porrett PM, Harris TH, Turka LA et al. Interleukins 27 and 6 induce STAT3-mediated T cell production of interleukin 10. Nat Immunol 2007; 8: 1363-1371.

130. Batten M, Li J, Yi S, Kljavin NM, Danilenko DM, Lucas S et al. Interleukin 27 limits autoimmune encephalomyelitis by suppressing the development of interleukin 17-producing T cells. Nat Immunol 2006; 7: 929-936.

131. Molle C, Goldman M, Goriely S. Critical role of the IFN-stimulated gene factor 3 complex in TLR-mediated IL-27p28 gene expression revealing a two-step activation process. $\mathrm{J}$ Immunol 2010; 184: 1784-1792.

132. Molle C, Nguyen M, Flamand V, Renneson J, Trottein F, De Wit D et al. IL-27 synthesis induced by TLR ligation critically depends on IFN regulatory factor 3. J Immunol 2007; 178: $7607-7615$. 
133. Shinohara ML, Kim J-H, Garcia VA, Cantor H. Engagement of the type I interferon receptor on dendritic cells inhibits $\mathrm{T}$ helper 17 cell development: role of intracellular osteopontin. Immunity 2008; 29: 68-78.

134. Pflanz S, Hibbert L, Mattson J, Rosales R, Vaisberg E, Bazan JF et al. WSX-1 and glycoprotein 130 constitute a signal-transducing receptor for IL-27. J Immunol 2004; 172 2225-2231.

135. Shinozaki Y, Wang S, Miyazaki Y, Miyazaki K, Yamada H, Yoshikai $\mathrm{Y}$ et al. Tumor-specific cytotoxic $T$ cell generation and dendritic cell function are differentially regulated by interleukin 27 during development of anti-tumor immunity. Int J Cancer 2009; 124: $1372-1378$.

136. Wang S, Miyazaki Y, Shinozaki Y, Yoshida H. Augmentation of antigen-presenting and Th1-promoting functions of dendritic cells by WSX-1(IL-27R) deficiency. J Immunol 2007; 179: 6421-6428.

137. Mascanfroni ID, Yeste A, Vieira SM, Burns EJ, Patel B, Sloma I et al. IL-27 acts on DCs to suppress the $\mathrm{T}$ cell response and autoimmunity by inducing expression of the immunoregulatory molecule CD39. Nat Immunol 2013; 14: 1054-1063.

138. Karakhanova S, Bedke T, Enk AH, Mahnke K. IL-27 renders DC immunosuppressive by induction of B7-H1. J Leukoc Biol 2011; 89: 837-845.

139. Matta BM, Raimondi G, Rosborough BR, Sumpter TL, Thomson AW. IL-27 production and STAT3-dependent upregulation of $\mathrm{B} 7-\mathrm{H} 1$ mediate immune regulatory functions of liver plasmacytoid dendritic cells. J Immunol 2012; 188: 5227-5237.

140. de Groot R, van Beelen AJ, Bakdash G, Taanman-Kueter EW, de Jong EC, Kapsenberg ML. Viral dsRNA-activated human dendritic cells produce IL-27, which selectively promotes cytotoxicity in naive CD8 + T cells. J Leukoc Biol 2012; 92: 605-610.

141. Liu Z, Liu JQ, Talebian F, Wu LC, Li S, Bai XF. IL-27 enhances the survival of tumor antigen-specific $\mathrm{CD} 8(+) \mathrm{T}$ cells and programs them into IL-10-producing, memory precursor-like effector cells. Eur J Immunol 2013; 43: 468-479.
142. Mayer KD, Mohrs K, Reiley W, Wittmer S, Kohlmeier JE, Pearl JE et al. Cutting edge: T-bet and IL-27R are critical for in vivo IFN-gamma production by CD8 T cells during infection. J Immunol 2008; 180: 693-697.

143. Morishima N, Owaki T, Asakawa M, Kamiya S, Mizuguchi J, Yoshimoto T. Augmentation of effector CD8 $+\mathrm{T}$ cell generation with enhanced granzyme B expression by IL-27. $\mathrm{J}$ Immunol 2005; 175: 1686-1693.

144. Schneider R, Yaneva T, Beauseigle D, El-Khoury L, Arbour N. IL-27 increases the proliferation and effector functions of human naive CD8 + T lymphocytes and promotes their development into Tc1 cells. Eur J Immunol 2011; 41: 47-59.

145. Tacken PJ, de Vries IJ, Torensma R, Figdor CG. Dendritic-cell immunotherapy: from ex vivo loading to in vivo targeting. Nat Rev Immunol 2007; 7: 790-802.

146. Malarkey MA, Witten CM. Approval Letter-Provenge. In: Administration USFaD, editor. BL 125197/0 2010.

147. Dhodapkar MV, Steinman RM, Krasovsky J, Munz C, Bhardwaj N. Antigen-specific inhibition of effector $T$ cell function in humans after injection of immature dendritic cells. $J$ Exp Med 2001; 193: 233-238.

148. Menges M, Rossner S, Voigtlander C, Schindler H, Kukutsch NA, Bogdan C et al. Repetitive injections of dendritic cells matured with tumor necrosis factor alpha induce antigen-specific protection of mice from autoimmunity. J Exp Med 2002; 195: 15-21.

149. Quintana FJ, Hagedorn PH, Elizur G, Merbl Y, Domany E, Cohen IR. Functional immunomics: microarray analysis of IgG autoantibody repertoires predicts the future response of mice to induced diabetes. Proc Natl Acad Sci USA 2004; 101(Suppl 2): 14615-14621.

150. Yeste A, Quintana FJ. Antigen microarrays for the study of autoimmune diseases. Clin Chem 2013; 59: 1036-1044.

151. Sanvicens N, Marco MP. Multifunctional nanoparticles-properties and prospects for their use in human medicine. Trends Biotechnol 2008; 26: 425-433. 